\title{
To screen or not to screen, that is the question. Or is it?
}

\author{
Leora B. Balsam, MD, and Abe DeAnda, Jr, MD
}

See related article on pages 1253-60 in the May issue.

In 2015, evidence-based medicine is the guiding principle behind the care of surgical patients. The science of medicine (as opposed to the art) is constantly evolving, and there are areas in this day and age where robust clinical practice guidelines are available to inform our decision making. More challenging are the areas where less evidence is available. One of these areas, the role of carotid artery stenosis screening prior to coronary artery bypass surgery, is evaluated by Masabni and colleagues ${ }^{1}$ in this issue of the Journal. In their Expert Review, Masabni and colleagues $^{1}$ ask, "Does preoperative carotid stenosis screening reduce perioperative stroke in patients undergoing coronary artery bypass grafting?"

There are several reasons to consider ordering a screening test for a patient before the operation. First, the test may provide clinical information that alters the surgical plan. Second, the results may help to stratify patient risk. This is important information to share with the patient during informed consent; in some cases, patients may opt for nonsurgical management when the balance of procedural risk exceeds its potential benefit. Risk assessment is also valuable to hospital systems during data collection for quality improvement programs; for example, the Society of Thoracic Surgeons National Database and the New York State Department of Health Cardiac Services Program collect data regarding preoperative surgical risk factors (including cerebrovascular disease) for patients undergoing coronary artery bypass surgery. These risk factors contribute to calculations of risk-adjusted mortality and therefore enable comparisons of institutional outcomes, individual surgeon outcomes, and outcomes over time. That said, Masabni and colleagues ${ }^{1}$ state that they are not attempting to evaluate the benefit of the screening test for risk stratification, but rather are focusing on whether screening reduces strokes.

\footnotetext{
From the Department of Cardiothoracic Surgery, New York University Langone Medical Center, New York, NY.

Disclosures: Authors have nothing to disclose with regard to commercial support.

Received for publication Feb 23, 2015; accepted for publication Feb 25, 2015; available ahead of print April 8, 2015.

Address for reprints: Leora B. Balsam, MD, Department of Cardiothoracic Surgery,

NYU Langone Medical Center, 530 First Ave, Suite 9V, New York, NY 10016

(E-mail: leora.balsam@nyumc.org).

J Thorac Cardiovasc Surg 2015;149:1485-6

$0022-5223 / \$ 36.00$

Copyright (c) 2015 by The American Association for Thoracic Surgery

http://dx.doi.org/10.1016/j.jtcvs.2015.02.054
}

We are taught as physicians primum non nocere, or first do no harm. So although preoperative screening tests may have potential benefits, these must be weighed against the inherent risks (and costs) that they pose. Risk encompasses the attendant proce-

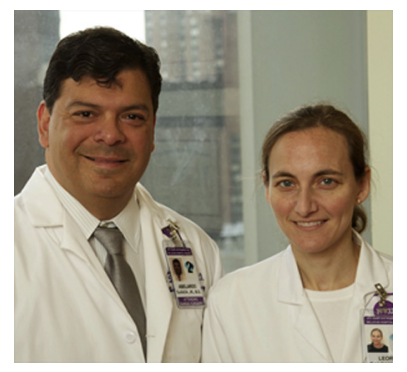
dural risks of the screening test itself, but it also extends to the risk of delaying surgical therapy while waiting for the screening test or its interpretation. Cost can be interpreted in terms of the cost to the patient as an individual and the cost to the health care system in general.

Screening for carotid artery stenosis is routinely performed with duplex ultrasonographic scanning. This noninvasive technology has both high sensitivity and specificity for detecting hemodynamically significant stenosis or occlusion. Profiling that is based on clinical variables, including age, presence of carotid bruit, peripheral artery disease, hypertension, and history of stroke or transient ischemic attack, can also predict carotid artery stenosis with relatively high sensitivity, but the specificity is low, resulting in a large number of false positives.

The incidence of stroke after coronary artery bypass surgery is relatively low (approximately $2 \%$ ), so expensive screening tests aimed at reducing this complication must target high-risk groups to be cost-effective. The cost of carotid duplex scanning is not insignificant, and a nonselective approach to screening before coronary artery bypass surgery is not financially viable. In addition, it remains clinically uncertain what is to be done with the information once it has been obtained. The role of staged and synchronous carotid artery revascularization (carotid endarterectomy or stenting) combined with coronary artery bypass grafting remains controversial. Masabni and colleagues ${ }^{1}$ review the existing data and conclude that "no direct causal relationship has been found between carotid artery stenosis and postoperative ipsilateral stroke, and the majority of strokes occur outside the territory supplied by the carotid artery." This may be the most critical statement of their review, because if the purpose of screening is to reduce the incidence of stroke but the positive result of a screen is not directly causally linked to the incidence of stroke, why screen at all?

There are limited clinical practice guidelines regarding preoperative carotid artery screening before coronary artery bypass grafting. The 2011 consensus statement of the American College of Cardiology Foundation and the 
American Heart Association Task Force gives the following class IIa recommendation ${ }^{2}$ : "Carotid artery duplex scanning is reasonable in selected patients who are considered to have high-risk features (ie, age $>65$ years, left main coronary stenosis, [peripheral artery disease], history of cerebrovascular disease [transient ischemic attack, stroke, etc], hypertension, smoking, and diabetes mellitus) (Level of Evidence: C)." A similar class IIa recommendation was presented in the 2011 guideline for the management of patients with extracranial carotid and vertebral artery disease ${ }^{3}$ : "Carotid duplex ultrasound screening is reasonable before elective [coronary artery bypass grafting] surgery in patients older than 65 years of age and in those with left main coronary stenosis, [peripheral arterial disease], a history of cigarette smoking, a history of stroke or [transient ischemic attack], or carotid bruit. (Level of Evidence: C)."

These recommendations stem from data showing that carotid artery disease is associated with increased stroke risk and mortality after cardiac surgery. This increased risk is more often not causally related to the stenosis itself but rather to concomitant diffuse atherosclerotic disease involving the ascending aorta or aortic arch. Carotid artery stenosis thus serves as a marker for the culprit aortic atherosclerotic disease.

Although there is clearly an association between carotid artery disease (particularly high-grade stenosis or occlusion) and stroke after cardiac surgery, most strokes actually occur in patients without significant carotid artery disease. In a retrospective review of 1499 patients undergoing major cardiac surgery, Adams and colleagues ${ }^{4}$ found that most patients $(69 \%)$ had no significant carotid artery stenosis on imaging studies. This and other studies make it clear that recognition of carotid artery disease through preoperative screening is not enough to distinguish most of the patients who will actually have a perioperative stroke.

Masabni and colleagues ${ }^{1}$ do not directly answer the question they pose in the title of their review, "Does preoperative carotid stenosis screening reduce perioperative stroke in patients undergoing coronary artery bypass grafting?" It seems that one can extrapolate from the data presented that the results of screening will result in a change in surgical plan that may reduce perioperative stroke for only a minority of patients. And for the majority of patients who do in fact have perioperative strokes, screening for carotid artery stenosis would not have predicted the complication beforehand. It would appear that in the era of big data, perhaps a more Bayesian approach to screening would result is a more positive answer to their question. In the meanwhile, it is likely that carotid screening before coronary bypass surgery will continue, if not only for the purpose of better risk stratifying patients and protecting the surgeon's interest in today's climate of defensive medicine.

\section{References}

1. Masabni K, Raza S, Blackstone EH, Gornik HL, Sabik JF. Does preoperative carotid stenosis screening reduce perioperative stroke in patients undergoing coronary artery bypass grafting? J Thorac Cardiovasc Surg. 2015; 149:1253-66.

2. Hillis LD, Smith PK, Anderson JL, Bittl JA, Bridges CR, Byrne JG, et al. 2011 ACCF/AHA guideline for coronary artery bypass graft surgery: executive summary: a report of the American College of Cardiology Foundation/American Heart Association Task Force on Practice Guidelines developed in collaboration with the American Association for Thoracic Surgery, Society of Cardiovascular Anesthesiologists, and Society of Thoracic Surgeons. J Am Coll Cardiol. 2011; 58:e123-210.

3. Brott TG, Halperin JL, Abbara S, Bacharach JM, Barr JD, Bush RL, et al; American College of Cardiology; American Stroke Association; American Association of Neurological Surgeons; American College of Radiology; American College of Radiology; Society of NeuroInterventional Surgery; Society for Vascular Medicine; Society for Vascular Surgery. 2011 ASA/ACCF/AHA/ AANN/AANS/ACR/ASNR/CNS/SAIP/SCAI/SIR/SNIS/SVM/SVS guideline on the management of patients with extracranial carotid and vertebral artery disease. A report of the American College of Cardiology Foundation/American Heart Association Task Force on Practice Guidelines, and the American Stroke Association, American Association of Neuroscience Nurses, American Association of Neurological Surgeons, American College of Radiology, American Society of Neuroradiology, Congress of Neurological Surgeons, Society of Atherosclerosis Imaging and Prevention, Society for Cardiovascular Angiography and Interventions, Society of Interventional Radiology, Society of NeuroInterventional Surgery, Society for Vascular Medicine, and Society for Vascular Surgery. Circulation. 2011;124:e54-130. Erratum in: Circulation. 2011;124:e146. Erratum in: Circulation. 2012;126:e26.

4. Adams BC, Clark RM, Paap C, Goff JM Jr. There is no benefit to universal carotid artery duplex screening before a major cardiac surgical procedure. Ann Vasc Surg. 2014;28:93-101. 